\title{
POLÍTICAS PÚBLICAS, AUTOIDENTIFICACIÓN Y ASOCIACIONES MAPUCHE EN EL GRAN CONCEPCIÓN, CHILE
}

\author{
Public Policies, Self-Identification and Mapuche Associations in the Greater \\ Concepción, Chile
}

\section{ANDREA ARAVENA* \& FRANCISCO JARA**}

Fecha de recepción: 13 de diciembre de 2018 - Fecha de aprobación: 17 de abril de 2019

\section{Resumen}

Se busca dar cuenta del aumento de la autoidentificación mapuche en el Gran Concepción, Chile, a partir de las solicitudes de reconocimiento de calidad de indígena y de constitución de asociaciones indígenas urbanas, gestionadas por la Corporación Nacional de Desarrollo Indígena (CONADI). Estos datos permiten sostener que el proceso de institucionalización de la demanda y la participación indígena en el marco de las políticas públicas implementadas desde los años noventa ha tenido su efecto más visible en el aumento de la autoadscripción étnica, lo que amplía las bases del autorreconocimiento mapuche y del reconocimiento por el Estado. En este sentido, formulamos la hipótesis de que tanto el Estado, a través de sus políticas de reconocimiento, y las organizaciones urbanas, a través de su institucionalización en asociaciones indígenas, han avanzado colaborativamente en la ampliación de lo que hasta la década de 1990 se entendía por identidad étnica en Chile.

Palabras clave: Mapuche; asociaciones; identidad; política pública.

\section{Abstract}

We aim to give an account for the increase in Mapuche self-identification in the Gran Concepción, Chile, based on the requests for recognition of indigenous status and the constitution of urban indigenous associations, managed by the National Indigenous Development Corporation (CONADI). These data make it possible to sustain that the process of institutionalization of indigenous demand and participation within the framework of public policies implemented since the 1990s has had its most visible effect in increasing ethnic self-identification, expanding the bases of Mapuche self-recognition and recognition by the State. In this sense we formulate the hypothesis that both the State, through its policies of recognition, and urban organizations, through its institutionalization in Indigenous Associations, have advanced collaboratively in the expansion of what until the 90 s was understood by ethnic identity in Chile.

Keywords: Mapuche; associations; identity; public policies.

* Dra. en Antropología social y etnología. Académica de la Facultad de Ciencias Sociales de la Universidad de Concepción, Chile. El artículo está enmarcado en el proyecto Fondecyt/Iniciación-Chile №11130384. Correo-e: andrea.aravena@udec.cl

** Antropólogo social. Servicio de Evaluación Ambienta, región de Ñuble, Chile. Correo-e: jarexskf@gmail.com 


\section{Introducción}

El Censo de 1992, que registró por primera vez la migración de personas mapuche a nivel nacional, dejó en evidencia no solo la existencia de casi un millón de personas que se autoidentificaron $^{1}$ como mapuche, sino que cerca de $80 \%$ de ellas residía en contextos urbanos (INE, 1992). Esta situación fue puesta de relieve desde los primeros trabajos sobre migración e identidad mapuche realizados en la década de 1990 en Chile (Ancan, 1994; Aravena, 1995; Curivil, 1999; Montecino, 1990a y 1990b). Aunque las primeras migraciones masivas de personas mapuche comienzan a fines del siglo XIX como resultado de una estrategia sistemática de homogenización étnica y radicación indígena por parte del Estado de Chile (Boccara y Seguel-Boccara, 1999) y del colonialismo de Estado que socavó la sociedad y cultura mapuche (Foerster, 2002), su identidad recién se hace visible, precisamente, en 1992 gracias a la autoidentificación (Montecino, Rebolledo et al., 1993; Aravena, 1995; Haughney y Marimán, 1993).

A partir de la promulgación en 1993 de la Ley Indígena 19.253 (MIDEPLAN, 1993) se incentiva, además, la creación de asociaciones indígenas $(\mathrm{Al})$, con el objeto de formalizar e institucionalizar su participación y canalizar acciones y recursos en el contexto de un nuevo período de relaciones entre el Estado y los indígenas en el país. Esto sucede en el marco de las políticas públicas denominadas "multiculturalismo neoliberal" (Hale, 2005) y "liberalismo multicultural" (Bolados, 2012, p. 135), cuyo propósito era la administración de las diferencias étnicas en un contexto de democracia política y libertad económica, pero que, mirado desde una perspectiva histórica y local, da cuenta del paso de un Estado monocultural a uno abierto al "reconocimiento étnico" (Foerster, Vergara \& Gunderman, 2017).

La complejidad de este fenómeno ha sido abordada desde distintos puntos de vista. Algunos estudios se han referido específicamente a los aspectos vinculados a la falta de tierras y la pobreza rural (Bengoa y Valenzuela, 1984); otros han tratado el tema de la búsqueda de oportunidades educativas y laborales (Huayquiñir, 1966, citado en Bengoa y Valenzuela, 1984); y unos más han profundizado en las trayectorias laborales de los inmigrantes y residentes mapuche en una u otra región (Torres y Aravena, 2016). Otros autores se han interesado en el racismo y la discriminación que afecta a los inmigrantes en los medios urbanos (Aravena, 2001; Merino, Quilaqueo \& Saiz, 2008; Pino y Merino, 2010; Zúñiga et al., 2017); en el rol de la memoria en la reconfiguración de la identidad (Aravena, 2003) o en la importancia de las organizaciones y las asociaciones de migrantes (Munizaga, 1961; Arancibia, 1999; Gissi, 2004) y en los aspectos rituales y religiosos como lugares contemporáneos de la memoria y la identidad indígena (Aravena, 1998; Cuminao \& Moreno, 1998; Henríquez \& Alcavil, 2007), por señalar algunos de los aspectos más analizados.

Respecto al tema de la asociatividad mapuche en la Región Metropolitana de Santiago y la presencia mapuche en el Estado, se ha sostenido "que el proceso asociativo mapuche se ha ido formalizando y ha permitido mayores espacios de institucionalización de sus demandas" (Campos, Espinoza \& De la Maza, 2018, p. 95). Con anterioridad existieron formas de autoidentificación y de organización como clubes deportivos y asociaciones de migrantes, descritos tempranamente por Munizaga (1961), pero cuyo vínculo con la burocracia estatal 
no era prioritario. En este mismo sentido y en relación con el Gran Concepción, en este trabajo daremos cuenta del aumento progresivo de asociaciones de indígenas urbanos y migrantes creadas a partir de la entrada en vigencia de la Ley 19.253 -veinticinco años atrás- que ha ido en paralelo con el aumento en la autoidentificación de personas con el pueblo mapuche con arreglo a la misma normativa.

Los aspectos teóricos y comparativos respecto de la migración mapuche y de la identidad homónima en Chile, especialmente en la Región Metropolitana de Santiago y también en la región del Biobío, pueden ser consultados en otros documentos de los autores de este artículo y de otros especialistas en el tema, algunos de los cuales hemos citado y reseñado en la bibliografía².

\section{Antecedentes acerca de la región y de la cuestión mapuche en los medios urbanos modernos}

La región del Biobío, tal y como se conoce hoy en día, fue creada hace cincuenta y cinco años, el 5 de diciembre de 1964. Se ubica en la zona centro sur de Chile y constituye, en términos demográficos, la segunda región del país -después de la Región Metropolitana de Santiago- con una población que bordearía los dos millones de habitantes (INE, 2017). La región se divide actualmente en tres provincias $^{3}$, siendo la más densamente habitada la provincia de Concepción, con cerca de un millón de habitantes, cuya capital provincial se sitúa en la comuna de Concepción. Fue fundada en 1550 por Pedro de Valdivia, bajo el nombre de Concepción de María Purísima del Nuevo Extremo, en la actual comuna de Penco o Pegnco y fungió como capital del Reino de Chile entre 1565 y 1573. La ciudad fue localizada en su actual emplazamiento en el valle de la Mocha, bahía de Concepción, luego del terremoto y maremoto de 1751 y construida en la ribera norte del río Bío Bío, considerado históricamente como la "frontera natural" norte del territorio mapuche.

El núcleo urbano de Concepción -denominado Gran Concepción ${ }^{4}-$ ejerce un significativo impacto en el comercio regional y nacional al ser parte de la región con más industrialización del país. Ciudad industrial por excelencia, fue epicentro de la industria del carbón, de la siderurgia, de la pesca y actualmente de la industria forestal y celulosa y es el principal centro económico del sur de Chile. A pesar de su relevancia histórica, política, económica y demográfica y de tener una importante concentración de población mapuche (INE 1992; 2002; 2012) es poco lo que se ha escrito sobre esta última (Klein, 2008).

En Chile, las estimaciones de población indígena son tan variables como sus fuentes y períodos de recolección de información. La población mapuche ha sido estimada en 928.060 personas en 1992 (INE, 1992), en 604.349 en 2002 (INE, 2002), en 1.508.722 en 2012 (INE, 2012, citado en Aravena, 2014), y en 1.745.147 en 2017 (INE, 2017), de acuerdo con las metodologías usadas para definir la adscripción étnica en cada uno de esos momentos. Esta población se localiza en su mayoría en zonas urbanas del país y concentra su ubicación en las regiones Metropolitana de Santiago, de la Araucanía y del Biobío, cuyo principal centro urbano es el Gran Concepción. En esta última región, la población indígena constituía un $13.11 \%$ de la población indígena del país en 
1992, un $7.8 \%$ en 2002 y un $9.58 \%$ en 2012 , y se identificaba con el pueblo mapuche en un 98.7\% en 2014 (Aravena, 2014) .

Ello da cuenta de un proceso de visibilización progresivo en el marco de un conjunto de medidas y políticas de reconocimiento y valorización de las identidades y de las lenguas de los pueblos originarios a nivel nacional e internacional impulsadas desde el año 1992. Nos referimos en particular a la aprobación de la denominada Ley Indígena № 19.253 y a la ratificación por parte del Estado de Chile del Convenio 169 de la Organización Internacional del Trabajo (OIT) (2008). En este contexto, a nivel nacional se verifica un aumento creciente y sostenido del reconocimiento de la calidad de indígena, y de la creación y la formalización de comunidades indígenas rurales y de asociaciones de indígenas urbanos y migrantes.

Hace menos de quince años atrás persistía la duda respecto de si la población mapuche residente en los medios urbanos de las regiones VIII y IX, especialmente Concepción y Temuco, se encontraba invisible o invisibilizada (Aravena, Gissi \& Toledo, 2005, p. 122), debido a que no se evidenciaba, en su caso, la notoriedad y la movilización que habían sido descritas en la Región Metropolitana de Santiago. Como se verá, sin embargo, la situación estudiada en la capital del país desde los años noventa para la población mapuche (Ancán, 1994; Aravena, 1995, 1999, 2002, 2003, 2014; Curilén, 1995; Curivil, 1999; Montecino, 1990a, 1990b; Montecino, S., Rebolledo \& otros, 1993; entre otros) puede también observarse nítidamente en el Gran Concepción.

Respecto de los estudios sobre migración mapuche, identidad y asociatividad, los trabajos han aludido a las dificultades del proceso migratorio y a los problemas de adaptación de los inmigrantes en el marco de una situación de ajuste interno, principalmente debido a las dificultades económicas sorteadas y a la discriminación percibida (Aguayo, 2006; Aravena, 1995, 1998; Cisternas, 2009; Quilaqueo, Merino \& Saiz, 2007; Merino \& Tocornal, 2012; Aravena \& Baeza, 2013; Aravena \& Cerda, 2018). Ello redundaría en largos períodos de negación de la identidad u ocultamiento de los orígenes y de visibilización de la identidad únicamente en el contexto de relaciones de confianza. Muchos autores han coincidido en la importancia del proceso de socialización familiar, los recuerdos de la niñez y el contacto con la comunidad de origen como elementos que ayudan a configurar la identidad en un principio (Aravena, 2003; Bello, 2002; Cisternas, 2009; Peyser, 2003) y que producen un proceso de retroalimentación entre el campo y la ciudad.

Mientras que las primeras generaciones que se establecen en la ciudad enfrentan la discriminación con el ocultamiento de su identidad e historia familiar, en una segunda etapa sus descendientes exteriorizan sus valores culturales con mayor seguridad (Merino \& Tocornal, 2012). Estos resignifican y refuerzan su adscripción identitaria, en un acto de volver a encontrarse consigo mismo, volver a encontrarse con su identidad, o de "renacer", en el que la memoria individual se articula y revincula a la memoria colectiva del pueblo (Aravena, 2003; Aguayo, 2006). En la primera etapa podía darse un sentimiento de ambivalencia respecto a lo que significa "ser-mapuche", en el que la identidad se asumía por condiciones externas: apellidos, relación con otros miembros de la familia, etc. Esta actitud es distinta a la de "sentirse-mapuche", pues esta aceptación implica un compromiso más profundo tanto a 
nivel espiritual como en la participación social (Merino \& Tocornal, 2012).

La mayoría de las investigaciones constatan como referentes identitarios objetivos relevantes el apellido, la lengua, los ritos, las celebraciones y la participación en asociaciones (Cuminao \& Moreno, 1998; Aravena, 1998). Paradójicamente, el apellido, que representa el pertenecer a un "nosotros", a un linaje (Cuminao \& Moreno, 1998), es, al mismo tiempo, un elemento detonante de la discriminación, pues configura las claves de la herencia y del legado (Tocornal \& Merino, 2012). Los soportes identitarios pueden ser catalizadores de una conciencia de adscripción étnica o de pertenencia a un pueblo, lo que conlleva un proceso reflexivo en el que los sujetos asumen su historicidad y se sienten parte de dicho pueblo. En esa toma de conciencia surge la diferenciación respecto del "otro" y se abre el camino a la organización y a la acción colectiva (Aravena, 2003; Aguayo, 2006; Antileo, 2006).

Un diagnóstico laboral en zonas urbanas desarrollado hace una veintena de años en comunas del Gran Santiago y del Gran Concepción (CONADI-OAIS-PET, 1999) determinó que en este último, $76,7 \%$ de los hombres mapuche era trabajador asalariado frente a $63,1 \%$ de las mujeres. Un $20,7 \%$ de estas estaba empleada en el servicio doméstico en Concepción y un $13 \%$ en Talcahuano, lugares donde el grueso de la población mapuche era oficial operario(a) $(22,6 \%)$ o artesano(a) (22,9\%). La rama de actividad más representada era la industria manufacturera. En ese momento no se distinguían formas particulares de organización mapuche en el medio urbano, pero sí se advertía que las personas pertenecientes a ese pueblo se encontraban insertas en diferentes tipos de organismos, como juntas de vecinos, partidos políticos, iglesias locales, clubes deportivos, federaciones y directivas estudiantiles $y$, especialmente, en el naciente Hogar de Estudiantes Mapuche en Concepción, Pegun Dungun (1989).

Casi dos décadas después, en una investigación sobre trayectorias laborales de personas mapuche en el Gran Concepción, se concluyó que estas se vieron fuertemente impactadas por el acceso de la población mapuche a la educación, que permitió su inclusión en nuevos espacios laborales con mayor estatus y calificación, lo cual implicó una "visibilización identitaria” más grande (Torres \& Aravena, 2016). Y ello a pesar de que aún persiste la inequidad en el acceso a la educación superior. El nivel educativo, precisamente, determina en gran parte las diferencias que se establecieron en este estudio entre las biografías laborales de los trabajadores mapuche de ambos sexos emigrantes de comunidades mapuche rurales y las de sus descendientes en el Gran Concepción. Las generaciones nacidas en el medio urbano, al mismo tiempo que se benefician de un acceso mayor a la educación secundaria y terciaria, deben, también, adaptarse a las transformaciones estructurales que se generaron en el mercado de trabajo con la disminución de la actividad industrial en la región a partir de los años noventa.

Así, se determinó que las generaciones de mujeres nacidas en el medio urbano se insertaron como profesionales de nivel medio en el servicio de la administración, como vendedoras, secretarias y otros, a diferencia de sus madres y abuelas, que lo hicieron principalmente en el servicio doméstico y como manufactureras. Igualmente, los varones nacidos en la ciudad dejaron de ser panaderos, sastres y operarios 
para emplearse como profesionales, administrativos, funcionarios públicos y trabajadores por cuenta propia. Se estableció, igualmente, que las nuevas generaciones de hombres y mujeres mapuche encontraron un trabajo especializado que requería de su "pertinencia cultural" en organismos del Estado, en instituciones de salud pública o educación, y que a partir de una creciente nueva demanda del mercado de consumo interno en torno a la cultura y a productos agropecuarios y artesanales, algunas personas se dedicaron al desarrollo de emprendimientos personales y familiares con un valor agregado asociado a la cultura y al patrimonio cultural mapuche.

A principios de los años noventa, otro estudio se refería a la configuración de tres orientaciones globales en la autopercepción de los mapuche como inmigrantes en la ciudad de Concepción, a saber, el tipo "integrativo" -que tendría un actitud individualista y asimiladora-; el "inadaptado" -que si bien valora la identidad mostraría una actitud "fatalista"-, y el "reconstructor de identidad" -referente a una persona crítica y constructiva- (Moltedo, 1990). Pocos trabajos se habían realizado hasta entonces sobre identidad mapuche en los medios urbanos y prácticamente ninguno en la ciudad de Concepción, a tal punto que en su momento se planteó la hipótesis de que en Concepción y Temuco "cambia el sentido de la resignificación de la identidad étnica y sus adscriptores [...]. En efecto, se constata que mientras más cerca se está de las comunidades, menos importante resulta resignificar la identidad" (Aravena, Gissi \& Toledo, 2005). Sin embargo, también se describió el surgimiento de manifestaciones políticas mapuches importantes en los medios urbanos de la región como constituyentes "de lo que tal vez llegará algún día a ser un movimiento mapuche en estas ciudades" (Aravena, Gissi \& Toledo, 2005).
Antecedentes complementarios a este trabajo que registraban la existencia de solo cinco asociaciones mapuches activas en el Gran Concepción en el año 2005 (Aravena, Gissi y Toledo, 2005) son dados a conocer en el amplio estudio de Cisternas, terminado apenas tres años después, donde se constata que en el año 2008 ya eran 13 asociaciones mapuches las existentes en esa misma zona (Cisternas, 2009, p. 78). Bajo los mismos supuestos investigativos, en 2011 se registró un aumento de dichas asociaciones a $17 \mathrm{y}$, al igual que en los trabajos realizados en el Gran Santiago, se advirtió que en el Gran Concepción las asociaciones mapuche tendían a arraigarse en ciertos barrios o sectores de determinadas comunas, con un importante peso del parentesco en cada una de ellas (Sepúlveda, 2011, p. 124).

En relación con las trayectorias y las rutas de migración, se ha sostenido, igualmente, que existe un contraste entre las personas mapuche que migran dentro del territorio histórico del Biobío al sur y quienes lo hacen a otros polos urbanos (Antileo, 2012). Del mismo modo, la identidad y la mantención de las prácticas culturales de los migrantes y los residentes en los centros urbanos son percibidas de distinta manera conforme se migra lejos de la comunidad rural o a poblados y ciudades cercanos, desde donde puede mantenerse un vínculo estrecho debido a la proximidad territorial.

De manera similar, con base en el análisis del significado del viaje de comuneros entre pequeños polos urbanos y la comunidad, se ha señalado que los habitantes mapuche de ciudades como Cañete, cercanas a Concepción, observaban con cierta distancia los discursos de los líderes y las ceremonias llevadas a cabo por estos en la gran urbe Santiago-, donde se gestan nuevos imaginarios 
de la identidad, lo que no sucedía en ciudades más cercanas a las comunidades, como Cañete o Concepción (Morales, 2005). Sin embargo, y también a partir del significado del viaje entre la comunidad mapuche rural y las ciudades de Cañete y Concepción, Milla (2015) concluye que en mujeres mapuche que hicieron ese traslado y migraron a Concepción se habían gestado nuevos imaginarios de la identidad mapuche.

Wittig, por su parte, apoyándose en la tesis que plantea la importancia de la consolidación de las asociaciones mapuches urbanas como nuevas estructuras organizacionales (Munizaga, 1961) que dan cuenta de un "despertar" de la sociedad mapuche urbana, estudia el uso del mapudungun en estos espacios urbanos (Wittig, 2009). En el caso de las asociaciones de la región del Biobío, releva que las prácticas lingüísticas de los hablantes urbanos de mapudungun tienen un sentido de estrategia de resistencia a la tendencia general de desplazamiento lingüístico y hegemonía cultural (Wittig, 2009, pp. 141 y 152).

Ya en la década de 1980, al alero del Centro Ecuménico Misión Urbana Rural (CEMUR) de la Iglesia Metodista, surge el centro cultural Lemun Antü con el objeto de fortalecer y reivindicar la identidad mapuche en Concepción a partir de expresiones como la danza y la revitalización del mapudungun (Catrilef, 2015). Luego, en la década de 1990 y con el asentamiento del primer hogar de jóvenes mapuche en Concepción Pegun Dugun, comienza a articularse y a cobrar protagonismo el tema mapuche en la ciudad con las primeras celebraciones de ceremonias. No obstante, sus discursos etnopolíticos seguían marcados por un corte ruralista, pues la mayoría de sus integrantes provenían de Arauco (Catrilef, 2015). Luego se crearían las asociaciones mapuche en el Gran Concepción.
En relación con estas, Catrilef (2017) ha estudiado el uso que las asociaciones indígenas urbanas han comenzado a hacer de los espacios públicos y privados de la ciudad, mismos que han sido resignificados y transformados en lugares de resistencia para materializar en ellos su identidad étnica (Catrilef, 2015, 2017). Respecto del "despertar" a la identidad mapuche de muchas personas pertenecientes a este pueblo en comunas del Gran Concepción, Navarrete (2015) logra pesquisar el renacer identitario de habitantes de Lota y Coronel, cuya identidad indígena se encontraba literalmente "oculta por el carbón" en tiempos en que la actividad minera constituía la principal fuente de trabajo y de articulación social de los trabajadores mapuche emigrados del campo. Veremos entonces cómo ha sido ese despertar tanto a nivel individual como asociativo.

\section{Antecedentes metodológicos}

Este artículo se sustenta en una investigación de carácter cualitativo y de naturaleza descriptiva, que estuvo orientada al estudio de los imaginarios sociales de la población mapuche en el Gran Concepción. Unos de sus objetivos específicos fue indagar en los registros de otorgamiento de calidad de indígena y de constitución de asociaciones indígenas en dicha área metropolitana. Para ello, entre 2013 y 2015 se realizó un trabajo etnográfico con personas, dirigentes y asociaciones mapuche, consistente en la observación etnográfica de las actividades de las organizaciones y las asociaciones, la aplicación de 62 entrevistas en profundidad a personas que autoidentificaban como mapuche y la conformación de 36 grupos de discusión, además de la recopilación de 
archivos atingentes a la constitución de calidad de indígena y de asociaciones y comunidades mapuche en el Gran Concepción. Asimismo, se recurrió al análisis de fuentes secundarias, principalmente con el objeto de conocer los avances y los estudios que se habían realizado sobre la temática, y se constató que en efecto eran muy pocos.

Los datos específicos a partir de los cuales se elaboraron las tablas y los mapas que aquí se dan a conocer fueron recopilados en la Dirección Regional de la Corporación Nacional de Desarrollo Indígena (CONADI), Cañete, entre julio de 2013 y marzo de 2014. La metodología de trabajo en los archivos de la CONADI fue la de la sistematización de la información a partir de los registros disponibles para consulta in situ. Debido a la falta de sistematicidad de la información consultada, hubo que contar y tabular cada uno de los registros de información a partir de la revisión de los documentos de "otorgamiento de calidad de indígena" y de "constitución de asociaciones y comunidades respectivamente".

Para el análisis de fuentes secundarias sobre la temática se efectuó una búsqueda de artículos científicos en las bases Web of Science, colección principal, y en Scopus y Latindex, índice general, para el período que va entre 1990 y 2014, en una primera instancia, y entre 2015 y 2018, en una revisión complementaria. El interés se centró en los aportes sobre la temática provenientes de investigadores e investigadoras adscritos a universidades de Latinoamérica. Para la búsqueda se utilizaron los tesauros: "mapuche", "migración", "urbano", "asociaciones" y "Concepción", en la categoría de artículos científicos. El tesauro debía hallarse en el título, palabras clave, resumen o cuerpo del manuscrito, de forma aislada o en conjunto con cualquiera de las otras palabras, pero siempre vinculadas a "Concepción". Los resultados de dicha búsqueda fueron sistematizados mediante el uso del software Atlas-T y posteriormente analizados de manera hermenéutica, integrando los contenidos de las publicaciones con sus respectivas citas al texto. Por último, también se consultaron memorias de título disponibles en la red que trataban directamente la temática ${ }^{6}$.

\section{Políticas públicas y calidad de indígena}

Como parte de lo que sería un nuevo trato con los pueblos indígenas, desde el retorno a la democracia en Chile en 1990, el Estado implementó distintas leyes y programas en su consideración y beneficio, entre los que destaca la Ley Indígena №19.253. Junto con su promulgación se creó la Corporación Nacional de Desarrollo Indígena (CONADI), encargada de la implementación de la política indigenista en el país. Con ambas instancias se inauguró un camino de reconocimiento identitario y asociativo y se establecieron nuevas formas de relación entre el Estado y los pueblos indígenas, mediatizadas por la burocracia estatal, en el marco de un proyecto político-cultural asociado a la multiculturalidad (Fernández \& Zapata, 2017).

Para tales efectos, se reconoció a las "etnias" y las culturas indígenas del país, su patrimonio y derechos culturales. Sin embargo, este reconocimiento se encuentra limitado, desde su génesis, por la Constitución Política de 1980, que resguarda los principios de un Estado unitario protector de los intereses privados en desmedro de la multiculturalidad y los derechos colectivos (Thiers, 2014; Foerster, 2002; Boccara \& Seguel-Boccara, 1999). Con la nueva legislación se trasladaron las luchas y 
las reivindicaciones étnicas a un nuevo espacio etnoburocrático "permitido", donde la política social se constituye como una zona de interacción y de lucha entre los agentes y la coerción propia de los contextos burocráticos (Boccara \& Bolados, 2008). No obstante, este contexto ha permitido también que cobren visibilidad identidades que antes o no se visibilizaban o no se significaban.

Uno de los efectos más visibles que esta política indígena ha tenido en materia de aceptación oficial de la identidad de las personas indígenas es el reconocimiento de la calidad de indígena, cuestión que llama bastante la atención si se consideran otras normas internacionales sobre la materia. En efecto, en Chile, para ser formalmente considerado como perteneciente a un pueblo originario no basta con sentirse parte del mismo, hablar una lengua indígena, poseer un apellido indígena o ser descendiente de personas indígenas, sino que esta condición debe acreditarse ante un órgano específico encargado de pronunciarse formalmente sobre el particular. De acuerdo con la Ley Indígena, la calidad de indígena se otorga por filiación, es decir, por ser hijo de padre o madre indígena descendientes de habitantes originarios de las tierras identificadas en la propia ley, poseer al menos un apellido indígena o por autoidentificación con alguna etnia indígena o filiación matrimonial ${ }^{7}$, excepto en el caso del pueblo rapanui, respecto del cual se eliminó la autoidentificación de personas no rapanui con dicho pueblo.

La misma norma sustenta el reconocimiento por parte del Estado de la condición de integrante de un pueblo indígena reconocido a nivel nacional. Este reconocimiento oficial permite el acceso a un conjunto de beneficios $y$, en menor medida, al cumplimiento de derechos para personas y culturas indígenas. La institución encargada de otorgar dicha calidad es la CONADI, cuya sede en la región del Biobío está localizada en la ciudad de Cañete. Dicha oficina posee jurisdicción en las regiones del Maule, Ñuble y Biobío.

El otorgamiento de la calidad de indígena se sitúa dentro de un contexto mayor, vinculado a una política pública que requiere, primero, identificar a los sujetos de dicha política. Los aspectos establecidos por la ley apuntan a criterios de parentesco, de territorialidad y de autoadscripción a la cultura. En la práctica, en la región, la mayoría de las certificaciones se otorgan actualmente por posesión de al menos un apellido indígena o por descendencia de alguien a quien se le ha reconocido su calidad de tal (es decir, por consanguineidad), o por autorreconocimiento o tener un cónyuge indígena, siendo "la tierra" o la pertenencia a un territorio el factor menos invocado por los solicitantes.

Ello queda demostrado, por ejemplo, a través de la revisión de muestras sistemáticas de solicitudes presentadas en la CONADI durante el tiempo de esta investigación, donde $99 \%$ de ellas fue aceptada de manera inmediata y solo una minoría rechazada. En dicha muestra, la causal más invocada para optar por la calidad de indígena fue la posesión del apellido, con un 98\% de aceptación. La segunda fue el autorreconocimiento o filiación matrimonial. En ninguna de las solicitudes analizadas se apelaba a la descendencia de habitantes originarios de las tierras identificadas como indígenas, por la dificultad que tienen las personas para acreditar la posesión de los títulos que señala la misma (letra a del artículo 2 de la Ley Indígena). 
La solicitud de acreditación de la calidad de indígena, como puede observarse en el cuadro № 1 , ha tenido un crecimiento significativo en los años considerados en esta revisión, tanto en su cantidad como en su relevancia, cifrándose su entrega en cerca de 65.000 certificados para ambas regiones, y siendo casi la totalidad de estos mapuche. La información data de 2001, pese a que la Ley Indígena entró en vigencia en 1993, pues antes de esa fecha no existía un registro sistematizado acerca de la cantidad de calidades otorgadas desde el inicio de la aplicación de la ley. Entre 2001 y 2007, las solicitudes ingresadas a la oficina regional de la CONADI, en Cañete, llegaron a un promedio de 94,3 por año, y entre 2008 y 2014 se produjo una fuerte alza, alcanzando en promedio las $8.606,8$ certificaciones al año, con un punto máximo de 20.110 solicitudes en 2012 (ver cuadro № 1).

\section{Cuadro $\mathrm{N}^{\circ}$ 1. Número de certificados de calidad de indígena entregados en la Dirección Regional Cañete de la CONADI para las regiones del Maule y el Biobío}

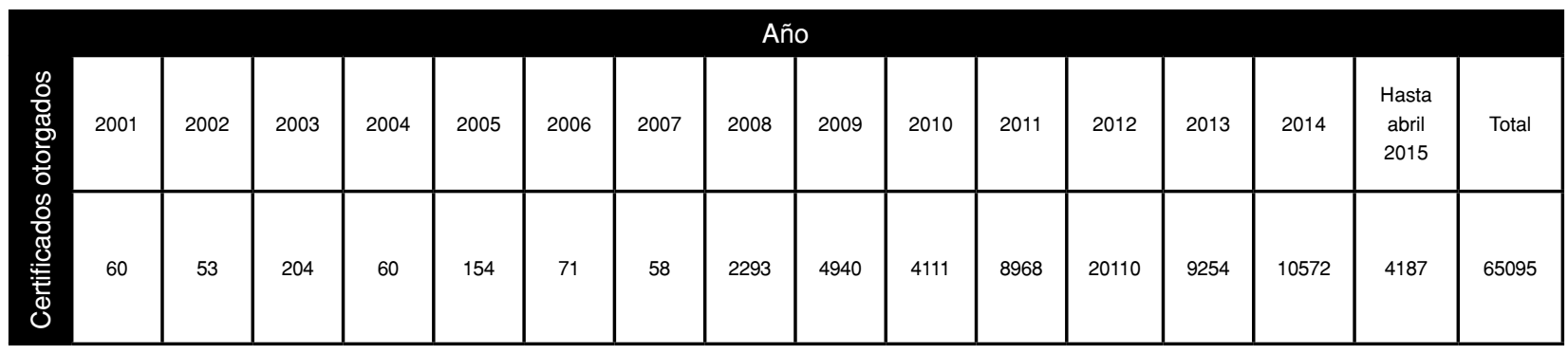

Fuente: Elaboración propia para proyecto Fondecyt 11130384

a partir de datos de la Oficina Regional de la CONADI.

También puede señalarse que existe una marcada relación entre el incremento de las solicitudes de calidad de indígena y determinados períodos del año. Estas aumentan explosivamente a partir de los últimos dos meses de cada año y hasta el mes de abril, lapso que coincide con períodos de postulación a concursos de proyectos y becas indígenas. Lo anterior cobró especial relevancia durante el primer mandato presidencial de Sebastián Piñera (11 de marzo de 2010-11 de marzo de 2014). El resto del año la demanda desciende. Esto nos lleva a pensar que el trámite de certificación de calidad de indígena ha cobrado la connotación de ser una suerte de "puerta de entrada" del individuo al sistema estatal, con su admisibilidad en programas como becas, fondos de desarrollo y de tierras indígenas, entre otros programas destinados a la población indígena por las distintas entidades públicas.

Precisamente, la CONADI no es la única institución a través de la cual la población mapuche se relaciona con el Estado. Existen diversas y variadas intervenciones de organismos públicos que abordan y trabajan el tema indígena desde sus propios fines, como el Instituto de Desarrollo Agropecuario (INDAP), el Servicio Nacional de la Mujer (SERNAM), el Servicio Nacional de Turismo (SERNATUR), el Servicio Nacional de 
Capacitación y Empleo (SENCE) o los Servicios de Salud, con los Programas Especiales de Salud y Pueblos Indígenas (PESPI), por ejemplo. Algunos de estos programas enfocados a indígenas se orientan a componentes identitarios y de contexto sociocultural, buscando el financiamiento de actividades de fortalecimiento organizacional o de la sociedad civil, de promoción de artes, artesanías y rescate del patrimonio turístico y cultural. Los programas y recursos destinados a los pueblos indígenas poseen poca articulación entre sí, lo que repercute, entre otras cosas, en sus bajos resultados e impactos potenciales. Cada institución tiene sus líneas programáticas y de financiamiento, las cuales no se encuentran vinculadas a un plan regional o comunal de desarrollo indígena o mapuche, ni a una propuesta mancomunada que busque dar respuesta a un diagnóstico común.

Frente a esta política pública dispersa y orientada a satisfacer una suerte de demanda indígena, las organizaciones y las personas toman distintas posiciones, considerando que se trata de un proceso voluntario. Algunos se movilizan hacia ella, otros deciden no formar parte, cuestionando su validez real, y otro grupo queda excluido por los criterios y estándares establecidos. No obstante, el efecto más visible tendría que ver con la opción de participar en la institucionalidad, viéndose reflejado esta en el aumento de la autoidentificación de las personas y la formalización de las organizaciones, en la medida en que responden a la demanda efectiva y manifestada en diversas instancias comunales y regionales de organizaciones mapuche locales. Así es como desde 2013 en adelante, distintas municipalidades han abierto oficinas de asuntos indígenas para atender estas demandas y visibilizar su acción en relación con la temática mapuche y la inter- culturalidad. Para acceder a los programas reservados a indígenas, estos servicios requieren y solicitan la acreditación de la calidad de indígena o de la constitución y registro de la respectiva asociación.

Además de los programas de gobierno orientados a la población mapuche a nivel nacional y regional, el aumento de la autoidentificación con el pueblo mapuche se ha visto también favorecido por un contexto social de mayor conocimiento y aceptación de este por la sociedad regional, y de un mayor interés de los medios de comunicación por dar cobertura a las actividades de las organizaciones y, en especial, a la posibilidad de integrarse o crear asociaciones y comunidades mapuche, como se verá.

\section{Políticas públicas y asociaciones indígenas}

No cabe duda de que Chile y América Latina, desde fines de los años ochenta han sido un campo fértil de germinación y crecimiento de lo que se ha denominado como la "emergencia" de organizaciones indígenas (Bengoa, 2000) en cuanto respuesta de la ciudadanía indígena a las tendencias etnocéntricas de los Estados nacionales.

La organización mapuche en medios urbanos, por su parte, tiene también larga data. Durante la segunda mitad del siglo XX se registra un patrón de integración sindical de los migrantes mapuche que llegaban a ejercer el oficio de panadero, además de las asociaciones y agrupaciones de carácter religioso y, posteriormente, político (Foerster \& Montecino, 1988) que se fueron formando e integrando al tejido social urbano. Las organizaciones indígenas en la ciudad han tenido un papel relevante en la 
continuidad y en el fortalecimiento de la identidad de origen. En algunos casos se ha estudiado la manera en que han llegado a reemplazar funcionalmente a la antigua familia extendida como medio de transmisión cultural indígena en la urbe (Aravena, 1999). De acuerdo con Peyser (2003), la ampliación de fronteras culturales en la ciudad mediante la asimilación de elementos wingka -no mapuche- a través de la urbanización y la educación, junto con la vigorización de las bases identitarias propias, serían las herramientas para lograr reivindicaciones a nivel de poder político. Al respecto, tanto Aguayo (2006) como Millaleo (2006) llegaron a sostener que la continuidad del pueblo mapuche en la ciudad dependería de la orientación que le den allí sus jóvenes al ser nacidos y criados en la ciudad.

Con la aplicación de la Ley Indígena, las organizaciones indígenas y mapuche en los medios urbanos se fortalecieron e institucionalizaron, con lo que fundamentaron un discurso representativo de habitantes de la ciudad. Por ejemplo, para 2004 Millaleo (2006) destacaba la existencia de un centenar de asociaciones en Santiago, con poca participación, pues el sistema permitía, además, que una persona pudiese pertenecer a más de una organización. Actualmente serían más de doscientas asociaciones (Carmona, 2014, citado en Sepúlveda \& Zúñiga, 2015). En este sentido, se ha sostenido que el Estado, mediante la paradoja de la exclusión (caso Ralco, forestales) y la inclusión (políticas indígenas) sustentó un ambiente favorable para que proliferaran las organizaciones urbanas (Varas, 2005). Al respecto Antileo (2012) ha señalado, de manera crítica, que el Estado mantiene de esta manera "el control efectivo del otro", mecanismo que involucra a distintas entidades a nivel global y local, que son las responsables de mantener bajo resguardo los límites en que las asociaciones se manifiestan y participan. Pero la existencia de dichas organizaciones, a nuestro juicio, también da cuenta en la actualidad de una ciudadanía indígena activa en los medios urbanos.

Bajo esta lógica, la CONADI ha cumplido un rol significativo, ejecutando proyectos y canalizando dineros a las oficinas de asuntos indígenas en las distintas comunas del país. Las demandas de este sector de la población circulan a través del trabajo local de los municipios, las juntas de vecinos y las asociaciones indígenas (Varas, 2005; Aguayo, 2006). Existe así una demanda canalizada a través de las organizaciones mapuche que de una $u$ otra forma es provista por el Estado chileno (Varas, 2005). Al respecto se ha dicho que el Estado operaría como una red que, independientemente del gobierno de turno, apoya al mapuche en los medios urbanos, separándolo del problema esencial que motiva su necesidad de emigrar, concediéndole derechos y soluciones individuales, sin reconocer derechos colectivos (Antileo, 2012). Pese a que, en general, las asociaciones mapuche desean superar la imagen esencialista que el Estado les ha impuesto (Curilén, 1995), la inversión se sigue centrando en los valores más visibles de la identidad: idioma, vestimentas, danzas, deportes (Antileo, 2012). De esta manera, las asociaciones "han sido fundamentales en el rescate, la difusión y la integración del mapuche urbano frente al proceso de aculturación y desarraigo propio del indígena migrante" (Arancibia, 1999, p. 98).

Millaleo (2006) ha sostenido que esta dependencia económica ha sido un obstáculo a la hora de complejizar los espacios de participación y visibilización, pues restringe las interpelaciones a temas individuales. Al respecto, 
Curilén (1995) señala que las demandas son tan variadas como el número de agrupaciones existentes, aunque existe el consenso de que las reivindicaciones tienen un carácter no solo cultural sino también político. Los diferentes intereses y posiciones han propiciado que la organización mapuche haya enfrentado un proceso de fragmentación importante de los núcleos centrales de reivindicación política e identitaria común. Esto los ha conducido a una situación de atomización en nuevas asociaciones, guiadas por intereses instrumentales y económicos, con una baja participación efectiva en las reuniones y las actividades (Millaleo, 2006). Esta crítica interna habría llevado, igualmente, a muchas organizaciones a buscar un compromiso y una figuración más política y no meramente instrumental.

Desde otro punto de vista, Aguayo (2006) considera que a partir de la década de 1990 se ha vivido un proceso de reflexión al interior de las organizaciones que ha derivado en un trabajo de coordinación entre distintas agrupaciones para aunar voluntades y establecer acuerdos con el fin de desarrollar una participación orientada a las reivindicaciones históricas y políticas. En el mismo sentido se ha señalado que en los medios urbanos los mapuche habrían pasado de la "exclusión" a la institucionalización de sus demandas, lo que se reflejaría en la existencia de las asociaciones indígenas, las oficinas de asuntos indígenas y la presencia mapuche en el Estado (Campos, Espinoza \& de la Maza, 2018, p. 95) en roles de facilitación intercultural.

En este contexto, en el Gran Concepción el aumento de las comunidades y las asociaciones ha sido significativo e importante durante las dos últimas décadas: en abril de 2015 se contabilizaban 32. No obstante, también hay muchas agrupaciones que no cuentan con el estatus otorgado por la CONADI de "comunidad o asociación indígena", así como muchas personas mapuche e indígenas que participan en agrupaciones de diversa índole y propósito, como ha sido costumbre históricamente, distintas a las asociaciones (sindicatos, federaciones estudiantiles, partidos políticos, etc.). En el caso de este trabajo, en lo relativo únicamente a las asociaciones indígenas urbanas -y en menor medida a las comunidades-, se observa no solo la aplicación de la institucionalidad vigente por parte de las mismas, sino también una resignificación de sus instituciones, además de que han acrecentado y visibilizado los procesos de autoidentificación que se han venido desarrollando desde los años ochenta y noventa.

La normativización organizacional con arreglo a la nueva ley tiene la funcionalidad de articular las demandas y potenciar los objetivos sociales, culturales y políticos de los pueblos originarios. Estas comunidades y organizaciones también poseen diferencias respecto de otras formas de organización denominadas tradicionales, lo cual hace resaltar su carácter ahistórico, así como la superposición de figuras nuevas, como las de presidente, vicepresidente y secretario, con otras como las de los lonco, los werken o los kimche. Desde la entrada en vigencia de la Ley 19.253 se han creado más de 300 comunidades y asociaciones indígenas mapuche en la región (ver cuadro № 2). De esta manera, las políticas de discriminación positiva, como ha sido afirmado, cumplieron un rol decidor en la conformación de organizaciones mapuche en la ciudad e influyeron en la potenciación de una identidad estratégica indígena para luego empezar a entretejer redes entre las asociaciones (Catrilef, 2015). 
Cuadro $N^{\circ}$ 2. Comunidades y asociaciones mapuche de la región del Biobío, por comuna ${ }^{8}$

\begin{tabular}{|c|c|c|c|c|}
\hline Provincia & Comunas & Comunidades & Asociaciones & $\begin{array}{c}\text { Suma de comunidades } \\
\text { y asociaciones }\end{array}$ \\
\hline \multirow[t]{7}{*}{ Arauco } & Cañete & 81 & 34 & 115 \\
\hline & Arauco & 28 & 24 & 52 \\
\hline & Los Álamos & 24 & 16 & 40 \\
\hline & Contulmo & 18 & 7 & 25 \\
\hline & Curanilahue & 0 & 4 & 4 \\
\hline & Lebu & 18 & 23 & 41 \\
\hline & Tirúa & 60 & 46 & 106 \\
\hline \multirow[t]{9}{*}{ Biobío } & Mulchén & 4 & 5 & 9 \\
\hline & Antuco & 0 & 1 & 1 \\
\hline & Alto Biobío & 13 & 37 & 50 \\
\hline & Quilaco & 2 & 0 & 2 \\
\hline & Santa Barbará & 4 & 4 & 8 \\
\hline & Los Ángeles & 3 & 4 & 7 \\
\hline & Negrete & 1 & 1 & 2 \\
\hline & Yumbel & 0 & 1 & 1 \\
\hline & Cabrero & 0 & 1 & 1 \\
\hline \multirow[t]{11}{*}{ Concepción } & San Pedro de la Paz & 1 & 8 & 9 \\
\hline & Concepción & 0 & 7 & 7 \\
\hline & Coronel & 2 & 4 & 6 \\
\hline & Hualpén & 0 & 2 & 2 \\
\hline & Talcahuano & 0 & 2 & 2 \\
\hline & Penco & 0 & 1 & 1 \\
\hline & Lota & 0 & 1 & 1 \\
\hline & Chiguayante & 0 & 3 & 3 \\
\hline & Santa Juana & 0 & 1 & 1 \\
\hline & Tomé & 0 & 2 & 2 \\
\hline & Hualqui & 0 & 1 & 1 \\
\hline \multirow{5}{*}{$\begin{array}{l}\text { Exprovincia de } \\
\text { Ñuble, actual } \\
\text { región de N̂̃uble }\end{array}$} & Chillán Viejo & 1 & 1 & 2 \\
\hline & Quirihue & 0 & 1 & 1 \\
\hline & El Carmen & 0 & 1 & 1 \\
\hline & Pinto & 0 & 1 & 1 \\
\hline & Coelemu & 0 & 1 & 1 \\
\hline TOTAL & & 260 & 245 & 305 \\
\hline
\end{tabular}

Fuente: Elaboración propia para proyecto Fondecyt 11130384 a partir de datos de la Oficina Regional de la CONADI, hasta abril de 2015. 
Se entiende por comunidad indígena a toda agrupación perteneciente a una misma etnia indígena y que se encuentre en una o más de las siguientes situaciones: que provenga de un mismo tronco familiar; reconozca una jefatura tradicional; posea o haya poseído tierras indígenas en común y/o provenga de un mismo poblado antiguo (Art. 9, Ley 19.253). La comunidad es la estructura orgánica más cercana a la forma "tradicional" que posee el pueblo mapuche y en su constitución se busca evitar la duplicidad de integrantes. La comunidad conserva parte de lo que fue su organización social antes de la llegada de los españoles, pero, sobre todo, da cuenta de un proceso histórico de organización impuesto primero por los españoles y luego por el Estado, a través del otorgamiento de títulos de merced y de la constitución de reducciones indígenas, respectivamente (González, 1986).

Las primeras organizaciones en constituirse en la zona lo hicieron en relación con los denominados títulos de merced. Algunas de ellas se asentaron en los mismos sitios que ocuparon sus antepasados, allí donde fueron radicados en reducciones. Por ello, la comunidad tiene un fuerte componente rural y territorial, aunque también se han creado algunas en sectores urbanos. Su número ha aumentado en los últimos veinte años.

Sobre su distribución en la región se observa que esta no es homogénea. La mayoría se sitúa en la provincia de Arauco, siendo las comunas de Cañete (81), Tirúa (60) y Arauco (28) las que poseen mayor cantidad (ver cuadro № 3 y mapa № 1). La provincia de Biobío le sigue como la segunda con más comunidades, 27 en total, con un centro neurálgico en la comuna de Alto Biobío, con 13 comunidades. Luego está la provincia de Concepción con 3 comunidades y la ex provincia de Ñuble con solo una comunidad a la fecha del trabajo (Ver Cuadro № 3). Sobre sus integrantes, el total de comuneros inscritos supera los 11 mil, conforme la información recopilada en esta investigación.

\section{Cuadro $\mathrm{N}^{\circ}$ 3. Registro de constitución de comunidades mapuche en la región del Biobío}

\begin{tabular}{|l|l|l|l|l|l|l|l|l|l|l|l|}
\hline Año & № & Año & № & Año & № & Año & № & Año & № & Año & № \\
\hline 1994 & 3 & 1998 & 9 & 2002 & 13 & 2006 & 10 & 2010 & 12 & 2014 & 15 \\
\hline 1995 & 4 & 1999 & 16 & 2003 & 12 & 2007 & 13 & 2011 & 12 & 2015 hasta abril & 7 \\
\hline 1996 & 1 & 2000 & 14 & 2004 & 6 & 2008 & 24 & 2012 & 13 & TOTAL & 245 \\
\hline 1997 & 6 & 2001 & 14 & 2005 & 10 & 2009 & 26 & 2013 & 5 & &
\end{tabular}

Fuente: Elaboración propia para proyecto Fondecyt 11130384 a partir de datos de la Oficina Regional de la CONADI, hasta abril de 2015. 


\section{Mapa $N^{\circ} 1$. Distribución de las comunidades mapuche en la región del Biobío}

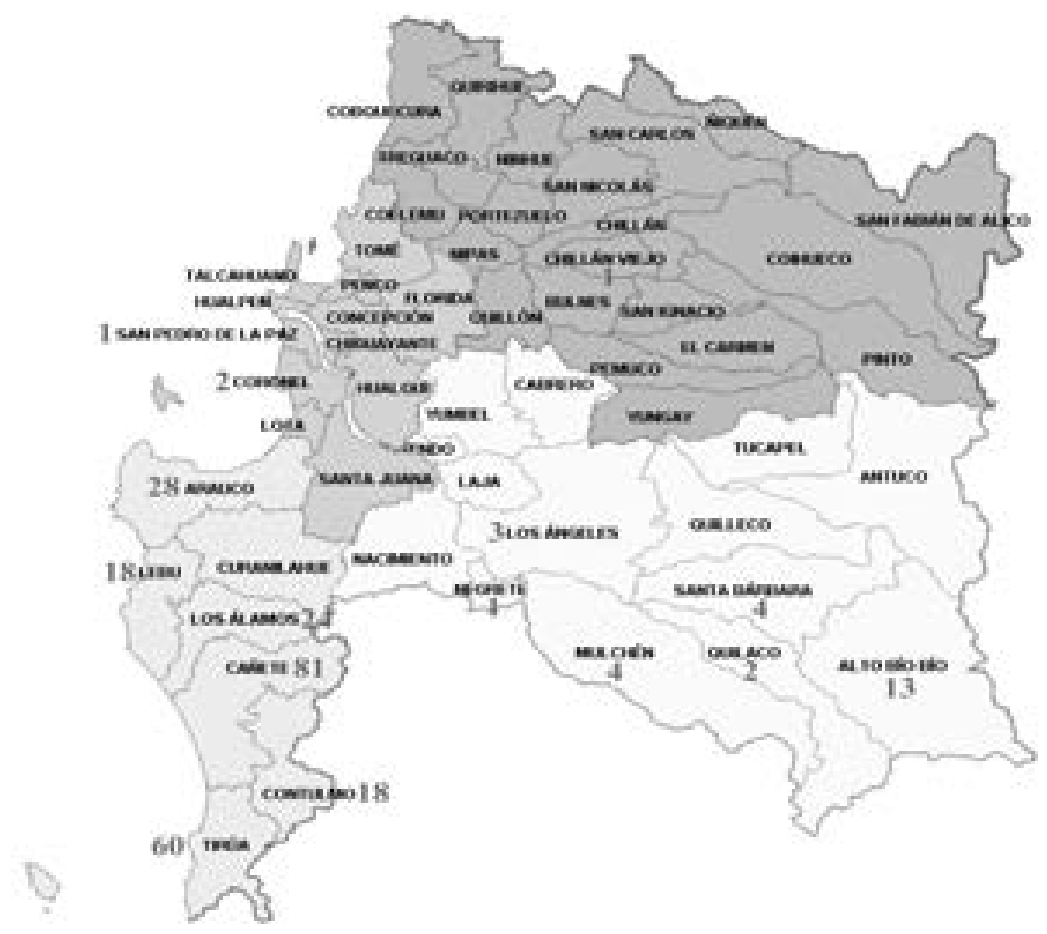

Fuente: Elaboración propia para proyecto Fondecyt 11130384 a partir de datos de la Oficina Regional de la CONADI, hasta abril de 2015.

En relación con las asociaciones, cabe señalar que se trata de una estructura nueva $y$, a diferencia de las comunidades, sin antecedentes previos en las sociedades indígenas. El fin de este tipo de organización es potenciar las actividades productivas y asociativas de indígenas "urbanos" y "migrantes" (Art. 76, Ley 19.253). La Ley Indígena se refiere a este colectivo como una "agrupación voluntaria y funcional integrada por, a lo menos, veinticinco indígenas que se constituyen en función de algún interés y objetivo común" (Ley 19.253). Se precisa, en la normativa mencionada, que esta forma de organización no representa de ninguna forma a una comunidad. Por su parte, cuando se constituyen las asociaciones, sus integrantes tienen que exponer cuáles serán sus fines u objetivos, los cuales pueden ser educacionales y culturales; profesionales comunes a sus miembros, o económicos, en la medida en que beneficien a sus integrantes, tales como agricultores, ganaderos, artesanos y pescadores, entre otros. A su vez, las personas pueden participar en varias asociaciones simultáneamente.

Las asociaciones así descritas han ido aumentando en número bajo características propias, ya que no requieren de los elementos de territorialidad que se les atribuyen a las comunidades. Por ende, pueden surgir gracias al acuerdo de distintas personas que posean la calidad de indígena, con independencia de su lugar de origen, comuna de procedencia u otro rasgo común, en la medida en que cumplan con los fines señalados. 
En la región del Biobío, las dos provincias con mayor cantidad de asociaciones son las mismas que cuentan con una cantidad mayor de comunidades. La provincia de Arauco registra 154 agrupaciones, equivalente a $62 \%$ del total regional (considerando las regiones del Biobío y Ñuble). Entre las comunas con mayor cantidad de asociaciones están Tirúa (46), Cañete (34) y Arauco (24). Por su parte, la provincia del Biobío es la segunda con más asociaciones (54) inscritas, pero su cantidad es tres veces menor que en la provincia de Arauco. La comuna de Alto Biobío marca la tendencia como núcleo contundente en la provincia del Biobío con 37 asociaciones. En tercer lugar está la provincia de Concepción con 32 asociaciones. Y, finalmente, la antigua provincia de Ñuble, donde hay una escasa expresión, con solo 5 de este tipo de colectividades. La totalidad de integrantes de estas asociaciones en la región asciende a más de 7.000 personas (ver Cuadro № 4 y mapa № 2).

\section{Cuadro $N^{\circ} 4$. Registro de constitución de asociaciones mapuche en la región del Biobío}

\begin{tabular}{|l|l|l|l|l|l|l|l|l|l|l|l|}
\hline Año & № & Año & № & Año & № & Año & № & Año & № & Año & № \\
\hline 1994 & 38 & 1998 & 8 & 2002 & 7 & 2006 & 7 & 2010 & 7 & 2014 & 26 \\
\hline 1995 & 18 & 1999 & 15 & 2003 & 10 & 2007 & 9 & 2011 & 7 & 2015 hasta abril & 6 \\
\hline 1996 & 11 & 2000 & 15 & 2004 & 4 & 2008 & 10 & 2012 & 9 & TOTAL & 270 \\
\hline 1997 & 9 & 2001 & 4 & 2005 & 19 & 2009 & 19 & 2013 & 12 & &
\end{tabular}

Fuente: Elaboración propia para proyecto Fondecyt 11130384 a partir de datos de la Oficina Regional de la CONADI, hasta abril de 2015.

\section{Mapa $N^{\circ}$ 2. Distribución de asociaciones mapuche en la región del Biobío}

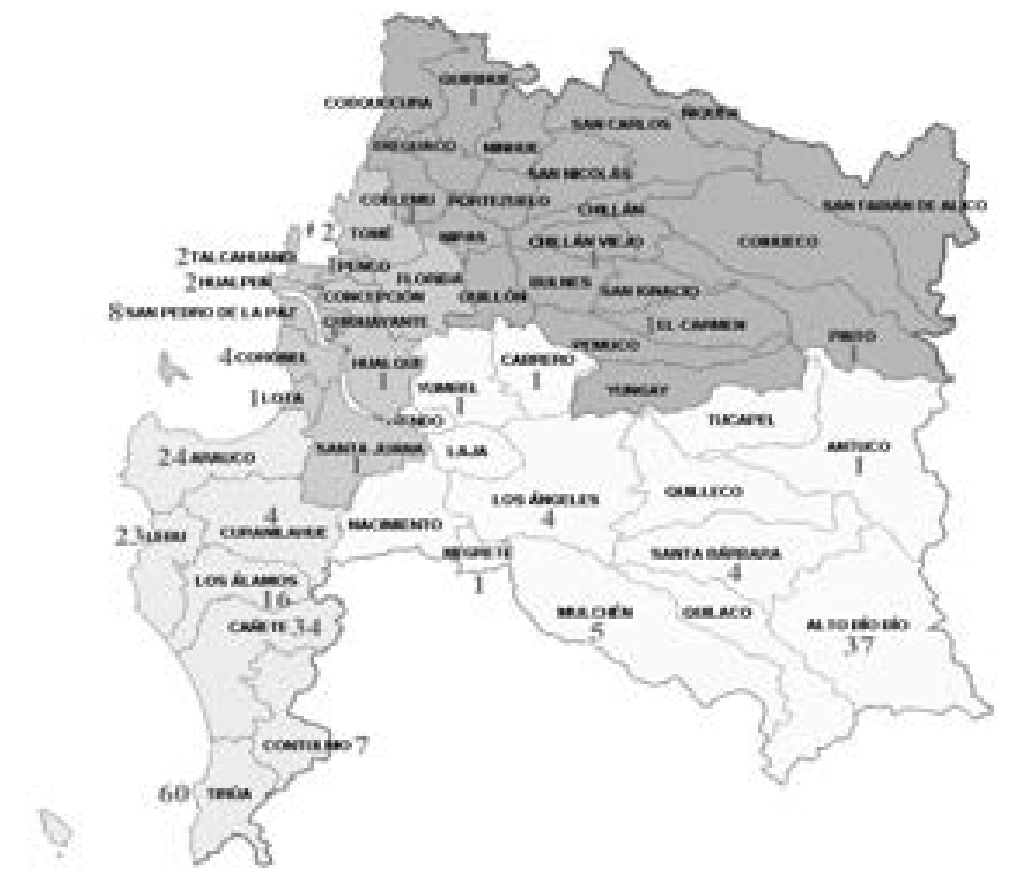

Fuente: Elaboración propia para proyecto Fondecyt 11130384 a partir de datos de la Oficina Regional de la CONADI, hasta abril de 2015. 
Las 32 asociaciones del Gran Concepción, a su vez, se distribuyen en 11 comunas: San Pedro de la Paz (8), Concepción (7), Coronel (4), Chiguayante (3), Hualpén (2), Talcahuano (2), Tomé (2), Penco (1), Lota (1), Hualqui (1) y Santa Juana (1). Su constitución data de entre 1998 y 2014 y la mayoía se mantienen activas, con directivas actualizadas. Las más antiguas se formaron en San Pedro de la Paz (1998), Hualpén (2000) y Concepción (2001), y las últimas (2014) en Santa Juana, Hualqui, Tomé y San Pedro la Paz (ver cuadro № 5). Estas asociaciones están integradas por entre 24 y 95 personas, muchas de ellas familiares entre sí y todas son mixtas.

Las actividades realizadas por estas asociaciones son múltiples y variadas. Cabe recordar que Imilan (2009) había señalado que la etnicidad mapuche en la ciudad emerge estratégicamente en distintas expresiones performativas. Sobre esta diversidad, durante el período de recolección de información para dar cuenta de este aspecto específico de la investigación en el Gran Concepción, el registro de actividades realizadas por las asociaciones fue:

- Celebraciones del Wetripantu o Año Nuevo Indígena, tanto a nivel central, en la plaza de Concepción, como en las diferentes comunas donde radican y se reúnen las organizaciones.

- Realización de conmemoraciones y celebraciones en el sector La Cascada del Parque Ecuador, comuna de Concepción, y en lagunas de la comuna de San Pedro de la Paz.

- Organización de seminarios y actos de discusión respecto de temas de interés, como los conflictos con el Estado chileno, en diferentes lugares públicos, académicos y abiertos a todo público.
- Actividades de carácter político vinculadas a la reivindicación de derechos del pueblo mapuche: marchas, actos públicos, actividades en la catedral (manifestaciones y "huelga de hambre") y en otros lugares, como universidades, plazas, centro cívico, con una alta notoriedad y difusión mediática, muchos de ellos en la comuna de Concepción, en los cuales han articulado objetivos comunes con movimientos socioambientales locales.

- Actividades de "apropiación o resignificación" de lagunas y parques, como las lagunas de San Pedro La Paz o la laguna Lo Galindo de Barrio Norte, donde se realizan rogativas, comidas tradicionales, juegos típicos y, en especial, competencias del juego de palin, espacios en los que se han establecido monolitos o símbolos de ocupación permanente, como el levantamiento de chemamul (hombres de madera) y rewe (altar vertical).

- Participación en programas de salud intercultural de pueblos originarios que impulsan los municipios de Concepción, Talcahuano y San Pedro La Paz.

- Postulación a fondos concursables enfocados a pueblos indígenas y procesos de consulta indígena llevados a cabo por distintas entidades estatales.

- Talleres de artesanía, platería e hilado para la comercialización.

- Encuentros y actividades con niños, vinculados a las diferentes organizaciones.

- Talleres de lengua y cultura, con hablantes nativos, en diversos espacios académicos y en las propias organizaciones. 
- Visita de sitios históricos y de interés (visitas históricas a Arauco); conmemoraciones históricas (Parlamento de Quilín, por ejemplo).
- Demanda de administrar la reserva nacional Nonguén, comuna de Concepción.

- Visita a presos mapuche en la cárcel de Concepción.

\section{Cuadro $\mathbf{N}^{\circ} 5$. Registro de constitución de asociaciones indígenas en la provincia de Concepción}

\begin{tabular}{|c|c|c|c|c|c|}
\hline & Nombre asociación & Comuna & $\begin{array}{l}\text { Año de } \\
\text { constitución }\end{array}$ & $\begin{array}{l}\text { Vigencia } \\
\text { directiva }\end{array}$ & $\begin{array}{l}\mathbf{N}^{\circ} \\
\text { socios }\end{array}$ \\
\hline 1 & ASOCIACIÓN INDÍGENA KARU MAPU & San Pedro de la Paz & 1998 & Expirada & 28 \\
\hline 2 & ASOCIACIÓN INDÍGENA ALIWEN & San Pedro de la Paz & 2003 & Expirada & 24 \\
\hline 3 & ASOCIACIÓN INDÍGENA KIÑE MILLARAY & San Pedro de la Paz & 2008 & Expirada & 76 \\
\hline 4 & ASOCIACIÓN INDÍGENA CHIWAYAN MEU & San Pedro de la Paz & 2008 & Expirada & 61 \\
\hline 5 & ASOCIACIÓN INDÍGENA FEY ALIWEN TAIÑ & San Pedro de la Paz & 2008 & No constituida & 32 \\
\hline 6 & ASOCIACIÓN INALTU LAFQUEN & San Pedro de la Paz & 2013 & Vigente & 45 \\
\hline 7 & ASOCIACIÓN MAPUCHE LAFQUENCHE PALIFE & San Pedro de la Paz & 2014 & Vigente & 34 \\
\hline 8 & ASOCIACIÓN INDÍGENA NEWEN LEUFU & San Pedro de la Paz & 2014 & Vigente & 27 \\
\hline 9 & ASOCIACIÓN INDÍGENA PEGUN DUGUN & Concepción & 2001 & Expirada & 28 \\
\hline 10 & ASOCIACIÓN INDÍGENA RUKA ALIWEN & Concepción & 2003 & Expirada & 25 \\
\hline 11 & ASOCIACIÓN INDÏGENA KURIÑANCO & Concepción & 2006 & Vigente & 29 \\
\hline 12 & ASOCIACIÓN INDÍGENA LIEF RAKIDUAM & Concepción & 2006 & Vigente & 34 \\
\hline 13 & ASOCIACIÓN NEWEN MAPU & Concepción & 2007 & Vigente & 65 \\
\hline 14 & ASOCIACIÓN INDÍGENA TRABUN HUECHELU & Concepción & 2009 & Vigente & 72 \\
\hline 15 & ASOCIACIÓN AUKINKO WALLMAPU & Concepción & 2013 & Vigente & 50 \\
\hline 16 & ASOCIACIÓN INDÍGENA RAYEN WENU & Coronel & 2007 & Vigente & 95 \\
\hline 17 & ASOCIACIÓN INDÍGENA NEWEN BOYEN & Coronel & 2010 & Vigente & 40 \\
\hline 18 & ASOCIACIÓN INDÍGENA TRIPAI ANTI & Coronel & 2010 & Vigente & 28 \\
\hline 19 & ASOCIACIÓN INDÍGENA KIMÜN LAFKENCHE & Coronel & 2013 & Vigente & 26 \\
\hline 20 & ASOCIACIÓN INDÍGENA MÜLLEN ANTU & Chiguayante & 2013 & Vigente & 58 \\
\hline 21 & ASOCACIÓN INDÍGENA RAYEN LEUFU & Chiguayante & 2013 & Vigente & 34 \\
\hline 22 & ASOCIACIÓN INDÍGENA CHIGUAYANTÚ & Chiguayante & 2013 & Expirada & 24 \\
\hline 23 & ASOCIACIÓN INDÍGENA NEHUEN TUIN PU PEÑI & Hualpén & 2000 & Vigente & 28 \\
\hline 24 & ASOCIACIÓN INDÍGENA HUALPEN WAJ-MAPU & Hualpen & 2008 & Vigente & 43 \\
\hline 25 & ASOCIACION INDIGENA TALCAHUEÑU ÑI FOLIL & Talcahuano & 2005 & Vigente & 26 \\
\hline 26 & ASOCIACIÓN WE PU REPÜ & Talcahuano & 2009 & Vigente & 31 \\
\hline 27 & ASOCIACIÓN INDÍGENA PEUMAYEN & Tomé & 2014 & Vigente & 28 \\
\hline 28 & $\begin{array}{l}\text { ASOCIACIÓN INDÍGENA GUERREROS DE LA COSTA } \\
\text { (WEYCHAFE LEFUEN) }\end{array}$ & Tomé & 2014 & Vigente & 28 \\
\hline 29 & ASOCIACIÓN INDÍGENA KOÑINTU LAFKEN-MAPU PENCO & Penco & 2009 & Vigente & 73 \\
\hline 30 & ASOCIACIÓN INDÍGENA EL COPIHUE LOTA & Lota & 2010 & Vigente & 36 \\
\hline 31 & ASOCIACIÓN INDÍGENA MAPUCHE MAWIDA CHE & Hualqui & 2014 & Vigente & 33 \\
\hline 32 & ASOCIACIÓN INDÍGENA BUTAMALLIN & Santa Juana & 2014 & Vigente & 25 \\
\hline
\end{tabular}

Fuente: Elaboración propia para proyecto Fondecyt 11130384 a partir de datos de la Oficina Regional de la CONADI. 
Cada asociación mapuche tiene distintos enfoques y a lo largo del año ejercen diversas actividades públicas. Por ejemplo, unas se orientan más a la ejecución de proyectos de índole cultural, otras a la conmemoración y celebración del año nuevo mapuche, a las actividades económico-productivas, al rescate patrimonial, o a actividades deportivas, gastronómicas, lingüísticas, políticas y de reivindicación de derechos, entre muchas. Otro ejemplo de participación asociativa local ha sido la relacionada con procesos de evaluación ambiental de proyectos, en los cuales han participado asociaciones indígenas y han presentado sus posiciones e intereses de manera activa frente al Estado, como es el caso de los procesos de consulta indígena llevados a cabo por el Servicio de Evaluación Ambiental (SEA) en la evaluación del proyecto Terminal GNL Penco-Lirquén con agrupaciones como la asociación indígena Koñintu Lafken Mapu en la comuna de Penco.

Especial impacto han tenido, a nivel regional, los momentos en que las asociaciones se han unido para enfrentar problemas comunes en torno a políticas que les atañen y han logrado expresarse con una sola voz como ciudadanía activa organizada frente al gobierno de turno. Tal fue el caso de la primera Red de Asociaciones Mapuche de la Provincia de Concepción conformada en 2010 bajo la demanda de administrar la reserva nacional Nonguén. Esta fue la primera muestra de autonomía en la ciudad (Catrilef, 2015). Ese mismo año se creó la Red de Asociaciones Mapuche de la Cuenca del Carbón, conformada por organizaciones de Coronel y Lota. En 2014 esta Red votó su rechazo a participar en la consulta indígena en materia de medioambiente ${ }^{10}$.
La adscripción a este tipo de colectividades ha sido destacada por sus integrantes como el elemento más relevante, a nivel colectivo, del reconocimiento de la identidad. Esta ha permitido la expansión de los límites identitarios antes establecidos por la comunidad rural. Sin embargo, también hay muchas personas que se identifican con la calidad de indígena sin que ello signifique una adscripción colectiva. En dicho caso, se elaboran discursos basados en los efectos positivos individuales que trae el reconocimiento de la calidad de indígena, en el sentido de permitirles postular a becas y subsidios. En ese caso existiría una suerte de desacoplamiento de la identidad respecto de las comunidades rurales, pues a través de las becas y otros beneficios las personas establecerían conexiones con una identidad interpersonal que no se encuentra necesariamente relacionada con la participación en un colectivo.

Por otro lado, cabría preguntarse si estas estructuras de reconocimiento de la calidad de indígena y asociativas limitan de alguna manera a los pueblos originarios en su capacidad para autodeterminarse fuera de los parámetros establecidos por la burocracia estatal y en qué medida les permiten relacionarse con otras organizaciones de la sociedad civil y no solamente, o principalmente, con las diversas instituciones del Estado. Lo anterior, ya que su reconocimiento obedece, en muchos casos, a los requisitos exigidos para el financiamiento de proyectos o de subsidios por parte de Estado. Por eso muchas de ellas se crean con el fin de acceder a dichos beneficios. En este proceso también se generan conflictos entre grupos, comunidades y asociaciones, con la posterior disgregación de sus integrantes en nuevos colectivos. 
No obstante, como ha quedado de manifiesto, también podría afirmarse que el aumento sostenido en el reconocimiento de la calidad de indígena y la conformación de asociaciones y comunidades indígenas puede ser indicador del desplazamiento y la expansión de las fronteras de la identidad en medios urbanos, ahí donde hace veinte o treinta años no se manifestaba con la misma fuerza. Ello ha generado visibilidad cultural e identitaria en cada una de las comunas donde estas asociaciones y comunidades desarrollan sus actividades, $y$ ha creado no solamente un marcado interés de identificación y participación de personas mapuche, sino también de personas no mapuche de la región. Así, el número de organizaciones y asociaciones mapuche ha aumentado año tras año. Estas han ido recuperando un sentido de práctica cultural y de alfabetización lingüística, visibilizando y politizado sus demandas y resistiendo a la asimilación cultural por parte de la sociedad hegemónica.

Tal y como ha sucedido en otras regiones del país, principalmente en la Región Metropolitana, el Gran Valparaíso, Maule o la Araucanía, donde la asociación cumple un rol de "comunidad urbana y un lugar de organización social y de construcción identitaria" (Aravena 1998, 2001; Arancibia, 1999; Vergara, Campos \& Farías, 2016), en el Gran Concepción las actividades de las asociaciones mapuche urbanas se han ido constituyendo en una de los principales espacios de manifestación, difusión identitaria y autonomía cultural étnica. El rol de las asociaciones y organizaciones podría ser el de un elemento "catalizador de los procesos de recuperación identitaria" (Peyser, 2003, p. 379). En estas asociaciones "la identidad no solo tendría orígenes históricos y tradicionales, sino también sería el resultado de procesos indivi- duales de revinculación con las identidades colectivas" (Aravena, 2014; Milla, 2015), en los que las elecciones individuales se encontrarían con los sustratos históricos de la identidad y los proyectos autónomos de los pueblos, en contraposición a los estereotipos heredados (idem).

Algunos autores han señalado que estos espacios organizativos serían una suerte de "neo-comunidad", un espacio de refugio cultural que le "permite al mapuche lejos de su mapu protegerse del awinkamiento" (Imilan \& Álvarez, 2008, p. 258). Ello ocurriría en el caso de problemas específicos, como la "pérdida de la lengua por migración", por ejemplo (Peyser, 2003). También se ha afirmado que "así como en la sociedad mapuche de las comunidades rurales el espacio social se construyó en torno al sistema reduccional, en la sociedad mapuche post-reduccional urbana, el espacio social de la comunidad se reconstruye en torno al sistema organizacional" (Aravena, 1999, p. 375). Nos parece relevante vincular aquí dichas asociaciones a que lo que se conoce como "organizaciones mediadoras"11 a nivel comunal, es decir, aquellas llamadas a proponer, difundiry, en última instancia, negociar los intereses de quienes representan ante los gobiernos comunales. En efecto, las asociaciones descritas también se han articulado en estructuras provinciales para hacer frente a sus problemas y hacer valer sus demandas a nivel de los gobiernos regionales.

\section{Comentarios}

Con la acreditación de la calidad de indígena y la conformación de asociaciones y comunidades, la visibilidad de la identidad mapuche en el Gran Concepción ha experimentado un notable incremento durante las últimas décadas. 
Esto puede verse como un resultado de las políticas de acción positiva implementadas en materia indígena tras el retorno a la democracia en Chile.

En relación con la pregunta respecto de si la población mapuche residente en los medios urbanos de la región del Biobío se encontraba invisible o invisibilizada debido a que, a pesar de su visibilidad estadística, no evidenciaba los procesos de resignificación identitaria y asociativa que habían sido consignados en la Región Metropolitana de Santiago, podemos afirmar que en la actualidad se encuentra en un proceso de visibilización creciente que ha dado paso a la conformación de nuevas comunidades y asociaciones de migrantes y urbanos. Hipotéticamente, ello podría dar cuenta de un "despertar" de la población mapuche urbana en el Gran Concepción a la luz de las políticas implementadas en materia indígena con el retorno a la democracia en Chile. Esta situación estaría igualmente vinculada a un proceso nacional de visibilización de los pueblos originarios y de empoderamiento del movimiento mapuche a nivel nacional y regional.

En este sentido, los datos que aquí presentamos nos llevan a sostener que el proceso de institucionalización de la demanda indígena en el marco de las políticas públicas implementadas desde la década de 1990 en Chile ha tenido su efecto más visible en el aumento de la autoadscripción étnica e identitaria, lo que ha ampliado las bases del autorreconocimiento mapuche y del reconocimiento por parte del Estado. En este sentido formulamos la hipótesis de que tanto el Estado de Chile, a través de sus políticas públicas de reconocimiento étnico, y las organizaciones mapuche en los medios urbanos, a través de las asociaciones indígenas, han avanzado colaborativamente en la ampliación de lo que hasta la década de 1990 se entendía por identidad étnica en Chile.

También, y esta vez referido únicamente a la asociatividad mapuche, los datos aquí expuestos nos permiten pensar en la existencia de cambios sustantivos a nivel regional respecto de los estudios desarrollados hasta la primera década de los años 2000. En efecto, como ya fue señalado en el acápite sobre asociatividad mapuche, recordemos que a fines de la década de 1980 en la región, a pesar de advertirse que las personas mapuche se encontraban insertas en diferentes formas de organización (juntas de vecinos, partidos políticos, iglesias, clubes deportivos, federaciones y directivas estudiantiles, Hogar de Estudiantes), no se distinguían formas particulares de organización mapuche en el medio urbano. Durante la primera década del siglo XXI ya había comenzado el proceso de institucionalización y formación creciente de asociaciones mapuche en el Gran Concepción (Aravena, Gissi \& Toledo, 2005; Aguayo, 2006; Sepúlveda, 2011). Junto a ellas comenzaba también el surgimiento de manifestaciones políticas mapuches importantes en los medios urbanos de la región, en miras a lo que podría constituirse en un movimiento mapuche (Aravena, Gissi \& Toledo, 2005). Para el mismo período se habla del uso de estrategias de resistencia a la tendencia general de hegemonía cultural (Wittig, 2009) y, a partir de la demanda de administrar la reserva nacional Nonguén, de la primera muestra de autonomía en la ciudad (Catrilef, 2015).

Por lo tanto, podemos plantear el supuesto de que a nivel regional, así como en otras ciudades del país y también en el caso de otros pueblos originarios en Chile, el tema del aumento de la 
autoidentificación étnica, de la asociatividad y de las crecientes reivindicaciones y demandas de espacios de autonomía y de administración de los mismos dan cuenta de una nueva configuración en el movimiento indígena en los medios urbanos. En el futuro este movimiento bien podría verse profundizado por otro tipo de acciones, como nuevos mecanismos de participación institucional o un eventual reconocimiento a nivel constitucional de la existencia de los pueblos indígenas en Chile.

A diferencia de las primeras organizaciones centradas en la recuperación y en la visibilización de la identidad, asistiríamos al surgimiento de un tipo de movimiento social indígena ligado a la reivindicación y la cooptación de espacios de lucha antes ocupados por otros actores sociales (sindicatos, partidos políticos) u otras

\section{Notas}

\footnotetext{
${ }^{1}$ En América Latina, los pueblos indígenas han reivindicado históricamente el derecho a definirse a sí mismos a través de la autodefinición o autoidentificación y del autorreconocimiento. En tal caso, "la autodefinición implica un ejercicio individual de determinación de su propia identidad cultural reconociéndose en aquella del grupo" (Aguilar Cavallo, G., 2006, p. 107) y el autorreconocimiento se entiende por "el derecho de la comunidad a definir sus propios miembros, en un ejercicio de identidad colectiva indígena" (idem). "La autoidentificación aparece así como un 'elemento definidor decisivo' en el reclamo de los pueblos indígenas para participar en la definición de ellos mismos y de los derechos que les corresponden" (idem).

${ }^{2}$ En relación con los trabajos sobre los mapuche, el antropólogo Rolf Foerster ha señalado "Los trabajos [...] sobre los mapuche urbanos comienzan con los artículos de Carlos Munizaga en la década de 1970 y hoy con una pléyade de investigadores donde destacan Sonia Montecino (1990a y b), Marcos Valdés (1998), Ramón Curivil (1999), Sara Mac Fall (1998) y Andrea Aravena (1999)" (Foerster, 2002).

${ }^{3}$ Estas son las provincias de Concepción, Arauco y Biobío. Cuando se recopiló el material de terreno relativo a las asociaciones, comunidades y calidades de indígena, la región estaba compuesta además por la provincia de Nuble, actualmente declarada Región
}

identidades locales (movimientos mineros), vinculado a un grupo social específico denominado "mapuche urbano" y a una identidad particular, la identidad mapuche. En este sentido, se trataría de un movimiento silencioso y creciente que daría cuenta de la construcción social de una acción ligada a un tipo de cambio social, en el sentido de Melucci \& Massolo (1991), en la sociedad chilena y en su propia historicidad.

Agradecimientos: Artículo desarrollado en el marco del Proyecto Fondecyt 11130384, "Imaginarios Sociales de la Identidad Mapuche en el Gran Concepción". La autora principal Andrea Aravena Reyes es investigadora responsable en el mismo y el co-autor Francisco Jara Santis, memorista.

del Ñuble. Para efectos prácticos, este artículo integró los datos de dicha nueva territorialidad a sus registros.

${ }^{4}$ El Gran Concepción corresponde al área metropolitana de Concepción y está compuesta por las mismas comunas de la provincia de Concepción, a excepción de Florida, de naturaleza rural, e incluye las comunas de Coronel, Chiguayante, Hualpén, Hualqui, Lota, Penco, San Pedro de la Paz, Santa Juana, Talcahuano y Tomé.

${ }^{5} \mathrm{~A}$ la fecha de corrección de este artículo (diciembre de 2018) aún no se disponía de datos desagregados del Censo de 2017 que vivo a subsanar las falencias metodológicas del Censo de 2012, razón por lo cual no se ha estimado prudente insistir en la revisión de dichas cifras.

${ }^{6}$ Las limitaciones de este artículo van en el sentido de no haber trabajado con registros de otro tipo de organizaciones indígenas, pero ello escapaba a los objetivos de la investigación. Sobre otras formas de asociatividad puede consultarse el estudio Caracterización de la asociatividad y la economía social de los pueblos indígenas, elaborado por la División de Asociatividad y Economía Social de la Subsecretaría de Economía y Empresas de Menor Tamaño del gobierno de Chile en 2015, cuyo objetivo fue caracterizar el sector asociativo de los pueblos indígenas que habitan en Chile identificando sus principales formas de asociatividad, necesidades específicas, 
problemáticas y oportunidades de desarrollo. Se trata de un estudio particularmente útil para el análisis de la asociatividad indígena vinculada a los "emprendimientos económicos".

${ }^{7}$ Se considerarán indígenas, para los efectos de esta ley, las personas de nacionalidad chilena que se encuentren en los siguientes casos: a) Los que sean hijos de padre o madre indígena, cualquiera sea la naturaleza de su filiación, inclusive la adoptiva; se entenderá por hijos de padre o madre indígena a quienes desciendan de habitantes originarios de las tierras identificadas en el artículo 12, números 1 y 2. b) Los descendientes de las etnias indígenas que habitan el territorio nacional, siempre que posean a lo menos un apellido indígena; un apellido no indígena será considerado indígena, para los efectos de esta ley, si se acredita su procedencia indígena por tres generaciones, y c) Los que mantengan rasgos culturales de alguna etnia indígena, entendiéndose por tales la práctica de formas de vida, costumbres o religión de estas etnias de un modo habitual o cuyo cónyuge sea indígena. En estos casos será necesario, además, que se autoidentifiquen como indígenas (Ley 19.253, Art. 2) (MIDEPLAN, 2003).

${ }^{8}$ Cabe hacer mención que existe una diferencia entre el número de colectividades indígena de esta tabla y una posterior que indica

\section{Referencias bibliográficas}

Aguayo, A. (2006). Organización mapuche en el espacio urbano: el caso de Meli Wixan Mapu en Santiago de Chile, 1991-2006. Informe de Seminario para optar al grado de Licenciado en Historia. Santiago: Universidad de Chile.

Aguilar, G. (2006). La aspiración indígena a la propia identidad. Universum, 21(1), 106-119. Recuperado de: https:// dx.doi.org/10.4067/S0718-23762006000100007

Ancán, J. (1994). Los urbanos, un nuevo sector dentro de la sociedad mapuche contemporánea. Penkun, (1), 5-15.

Antileo, E. (2006). Mapuches santiaguinos: posiciones y discusiones del movimiento mapuche en torno al dilema de la urbanidad. Recuperado en: http://meli.mapuches.org/IMG/pdf/ MAPUCHE_URBANOS_PARA.pdf

(2012). Nuevas formas de colonialismo: diáspora mapuche y el discurso de la multiculturalidad. Tesis para optar al grado de Magíster en Estudios Latinoamericanos. Santiago: Universidad de Chile.

Arancibia, M. (1999). Un acercamiento a la cultura y problemática mapuche a través de la bibliotecología. (Tesis inédita de licenciatura). Universidad de Playa Ancha, Valparaíso.

Aravena, A. (1995). Desarrollo y procesos identitarios en el mundo indígena urbano. En Tierra, territorio y desarrollo indígena (pp. 171-178). Temuco: Instituto de Estudios Indígenas-Universidad de la Frontera..

(1998). La identidad indígena en los medios urbanos. los años en los cuales se registra la inscripción de dichos grupos, la cual se explica por la manera en que la CONADI consigna la información en distintos tipos de archivos.

${ }^{9} \mathrm{Al}$ momento de corregir este artículo (diciembre de 2018) se actualizó la información contenida en este cuadro y se verificó que ninguna otra asociación había sido incorporada al registro de la CONADI desde 2014.

${ }^{10}$ El miércoles 3 de septiembre de 2014, la página de Biobío Chile.cl, publicaba: "Mapuche de Concepción rechazan participar en Consulta Indígena del Gobierno. El rechazo de las comunidades de la provincia de Concepción a la Consulta Indígena está sustentada en la desconfianza al proceso, recalcaron en su declaración una serie de organizaciones mapuche de la zona [...] dos mujeres leyeron una declaración, donde exigieron la anulación de los decretos 124, 66 y 40, porque insisten que en materia de Evaluación Medioambiental, por ejemplo, favorecen los intereses empresariales" (Recuperado en: https://www.biobiochile. cl/noticias/2014/09/03/mapuche-rechazan-participar-en-consultaindigena-del-gobierno-en-concepcion.shtml).

${ }^{11}$ Sobre las "instituciones mediadoras" (no organizaciones), véase el interesante artículo de Vergara, Foerster \& Gundermann (2005).

Procesos de recomposición de la identidad étnica mapuche en la ciudad de Santiago. En Actas III Congreso Chileno de Antropología (pp. 1121-1133). Temuco: Colegio de Antropólogos de Chile.

(1999). Identidad indígena en los medios urbanos. En Boccara, G. \& Galindo, S. (Eds.). Lógica mestiza en América (pp. 165-199). Temuco: Instituto de Estudios Indígenas-Universidad de la Frontera.

(2001). La diáspora invisible. El Correo de la Unesco, $54(9), 18-20$

(2002). Los mapuche-warriache: migración e identidad mapuche urbana en el siglo XXI. En Boccara, G. (Ed.), Colonización, resistencia y mestizaje en la América. Siglos XVI-XX (pp. 365-381). Quito: Abya-Yala.

(2003). El rol de la memoria colectiva y de la memoria individual en la conversión identitaria mapuche. Estudios Atacameños, (26), 89-96.

(2014). Identidad indígena en Chile en contexto de migración, urbanización y globalización. Les Cahiers Amérique Latine Histoire et Mémoire, (27), en línea. Recuperad de: http:// alhim.revues.org/4942

Aravena, A. \& Baeza, M. (2013). Violencia simbólica en el Chile contemporáneo. Estrategias de respuesta. Revista Internacional de Sociología (RIS), (3), 543-565.

Aravena, A. \& Cerda, C. (2018). Indígenas urbanos en Chile: imaginarios sociales de la identidad mapuche en la frontera del 
Biobío. En Horbath, J. \& Gracia, M. (coordinadores) La cuestión indígena en las ciudades de las Américas Procesos, políticas e identidades.., Buenos Aires: Imprenta Dorrego.

Aravena, A., Gissi, N. \& Toledo, G. (2005). Los Mapuche más allá y más acá de la frontera: identidad étnica en las ciudades de Concepción y Temuco. Sociedad Hoy, (8-9), 117-133.

Bello, Á. (2002). Migración, identidad y comunidad mapuche en Chile: en utopismos y realidades. Asuntos Indígenas, (3), 40-47.

Bengoa, J. (2000). La emergencia indígena en América Latina. México: Fondo de Cultura Económica.

Bengoa, J. \& Valenzuela, E. (1984). Economía mapuche. Santiago: PAS.

Boccara, G. \& Seguel-Boccara, I. (1999). Políticas indígenas en Chile (siglos XIX y XX): de la asimilación al pluralismo. El caso mapuche. Revista de Indias, LIX (217), 742-774.

Boccara, G. \& Bolados, P. (2008). ¿Dominar a través de la participación? El neoindigenismo en el Chile de la postdictadura. Memoria Americana, 16(2), 167-196.

Bolados, P. (2012). Neoliberalismo multicultural en el Chile postdictadura: la política indígena en salud y sus efectos en comunidades mapuches y atacameñas. Chungara, 44(1), 135-144.

Campos, L., Espinoza, C. \& De la Maza, F. (2018). De la exclusión a la institucionalidad. Tres formas de expresión mapuche en Santiago de Chile. Andamios, 15(36), 93-112. Recuperado en: http://dx.doi. org/10.29092/uacm.v15i36.603

Catrilef, A. (2015). Identidades ofendidas, memorias desplazadas y lugares de resistencia: una mirada desde las y los Mapuche de la Provincia de Concepción. (Tesis inédita de licenciatura). Universidad de Concepción, Chile.

(2017). We kuruv mapuche pu kara mew: nuevos vientos mapuche en las ciudades. Identidades (in)visibles, memorias desplazadas y lugares de resistencia: propuestas de los Mapuche en Concepción. Editorial Académica Española..

Cisternas, E. (2009). Proceso de construcción de la identidad mapuche en miembros de asociaciones indígenas urbanas en el Gran Concepción. (Tesis inédita de licenciatura). Universidad de Concepción, Concepción.

CONADI-OAIS-PET (1999). Estudio de pre-factibilidad para un programa de inserción laboral respecto de población indígena en zonas urbanas, diagnóstico y propuestas de inserción laboral indígena, regiones Metropolitana y Octava. Temuco: Pillán.

Cuminao, C. \& Moreno, L. (1998). El gijatun en Santiago. Una forma de reconstrucción de la identidad mapuche. (Tesis inédita de licenciatura). Universidad Academia de Humanismo Cristiano, Santiago.

Curilén, E. (1995). Organizaciones indígenas urbanas en la Región Metropolitana. En Tierra, territorio y desarrollo indígena (179-186). Temuco: Instituto de Estudios Indígenas-Universidad de la Frontera.

Curivil, R. (1999). Los cambios culturales y los procesos de reetnificación entre los Mapuches urbanos. (Tesis para la obtención del grado de Magíster en Ciencias Sociales). Santiago: Universidad Academia de Humanismo Cristiano.
Fernández, J. \& Zapata, J. (2017). Política cultural e identidad indígena: un análisis desde la interculturalidad crítica para el caso de la Araucanía. Documento de trabajo ICSO № 41/2017, Escuela de Sociología-Universidad Diego Portales, Santiago.

Foerster, R. (2002). Sociedad mapuche y sociedad chilena: la deuda histórica. Polis, (10). Recuperado en: https://journals. openedition.org/polis/7829

Foerster, R. \& Montecino, S. (1988). Organizaciones, líderes y contiendas mapuche (1990-1970). Santiago: Centro de Estudios de la Mujer.

Foerster. R., Vergara, J. \& Gunderman, H. (2017). "Dos siglos de política indígena republicana. Del Estado monocultural al reconocimiento étnico". En Rengifo, F. (Ed.), Historia política de Chile, 1810-2010. Tomo II. Estado y sociedad (pp. 205-242). Santiago: Fondo de Cultura Económica, Universidad Adolfo Ibáñez.

Gissi, N. (2004). Los mapuche en el Santiago del siglo XXI: desde la ciudadanía política a la demanda por el reconocimiento. Cultura Urbana, (1).

González, H. (1986). Propiedad comunitaria o individual. Las leyes indígenas y el pueblo mapuche. Nütram, I(3).

Hale, C. (2005). Neoliberal Multiculturalism. PoLAR: Political and Legal Anthropology Review, (28), 10-19. Recuperado en: https://doi. org/10.1525/pol.2005.28.1.10

Haughney, D. \& Marimán, P. (1993). Población mapuche: cifras y criterios. Documento de trabajo 1, Centro de Estudios y Documentación Mapuche Liwen.

Henríquez, S. \& Alcavil, X. (2007). Significados, usos y representaciones mapuche del rewe en los espacios urbanos de la región metropolitana. Santiago: Universidad Academia de Humanismo Cristiano.

Imilan, W. (2009). Urban Ethnicity in Santiago de Chile. Mapuche Migration and Urban Space. (Tesis inédita de doctorado). Universidad Técnica de Berlín, Berlín.

Imilan, W. \& Álvarez, V. (2008). El pan mapuche. Un acercamiento a la migración mapuche en la ciudad de Santiago. Revista Austral de Ciencias Sociales, (14), 23-49.

INE (Instituto Nacional de Estadísticas) (1992). Censo de Población y Vivienda 1992. Santiago: INE.

Santiago: INE. (2002). XVI Censo Nacional de Población y V de Vivienda. (2012). XVIII Censo Nacional de Población y VII de Vivienda. Santiago: INE.

(2017). XIX Censo Nacional de Población y VIII de Vivienda. Santiago: INE.

Klein, F. (2008). Los movimientos de resistencia indígena. El caso mapuche. Gazeta de Antropología, (2/2008). Recuperado en: http:// www.ugr.es/ pwlac/G24_04Fernando_Klein.html.

Merino, M., Quilaqueo, D. \& Saiz, J. (2008). Una tipología del discurso de discriminación percibida en mapuches de Chile. Signos, 41(67), 279-297.

Merino, M. \& Tocornal, X. (2012). Posicionamientos discursivos en la construcción de identidad étnica en adolescentes mapuches 
de Temuco y Santiago. Signos, 45(79), 154-175.

MIDEPLAN (1993). Ley Indígena № 19.253. Recuperado en: http://www.uta.cl/masma/patri_edu/PDF/Leylndigena

Milla, N. (2015). "Domo miaumekely ci nampvlkafe". Aproximación a los significados del viaje entre ciudad y campo en la identidad de mujeres mapuche en la provincia de Concepción. (Tesis inédita de licenciatura). Universidad de Concepción, Chile.

Millaleo, A. (2006). Organizaciones mapuche urbanas en la RM. ¿Incremento en la participación mapuche o fragmentación organizacional? (Tesis inédita de Sociología). Universidad Arcis, Santiago.

Melucci, A. \& Massolo, A. (1991). La acción colectiva como construcción social. Estudios Sociológicos, 9(26), 357-364.

Montecino, S. (1990a). El mapuche urbano: un ser invisible. Creces, (13), 30-48.

(1990b). Transformación y conservación cultural en la migración mapuche a la ciudad. Creces, (19), 28-34.

Montecino, S., Rebolledo, L., Willson, A. \& Campos, L. (1993). Diagnóstico sobre inserción laboral de mujeres mapuche rurales y urbanas. Santiago: Ediciones PIEG, SERNAM y Facultad de Ciencias Sociales de la Universidad de Chile.

Moltedo, R. (1990). Emigración mapuche e identidad étnica. El Canelo, 5(22), 14-16.

Morales, C. (2005). Aproximación sociológica a las percepciones del Lafquenche, respecto a su interacción cotidiana con el medio urbano en una ciudad cercana a las comunidades. (Memoria de título para optar al grado de Sociólogo). Concepción: Universidad de Concepción.

Munizaga, C. (1961). Estructuras transicionales en la migración de los Araucanos de hoy a la ciudad de Santiago de Chile. Santiago: Editorial Universitaria.

Navarrete, G. (2015). Ocultos por el carbón. Procesos identitarios y urbanización del pueblo Mapuche. Una aproximación a la realidad en la comuna de Coronel y Lota, región del Biobío. (Tesis inédita de licenciatura). Universidad de Concepción, Chile.

Peyser, A. (2003). Desarrollo, cultura e identidad: el caso del mapuche urbano en Chile. Elementos y estrategias identitarias en el discurso indígena urbano. (Tesis inédita de doctorado), Faculté des sciences économiques, sociales et politiques de l'Université catholique de Louvain, nouv. Sér. № 413. Louvain: Université Catholique de Louvain.
Pino, A. \& Merino, M. (2010). Discriminación e identidad étnica en el discurso oral de adolescentes mapuches en contexto escolar de la ciudad de Temuco. Discurso \& Sociedad, 4(1), 103-119.

Sepúlveda, B. (2011). Recompositions territoriales autochtones en milieu urbain: urbanisation et urbanité mapuche au Chili. Recherches amérindiennes au Québec, 41(2-3), 117-128.

Sepúlveda, B. (2015). Geografías indígenas urbanas: el caso mapuche en La Pintana, Santiago de Chile. Revista de Geografía Norte Grande, (62), 127-149.

Quilaqueo, D., Merino, M. \& Saiz, J. (2007). Representación social mapuche e imaginario social no mapuche de la violencia percibida. Revista Atenea, (496), 81-103.

Thiers, J. (2014). Santiago mapuche. La dimensión indígena del espacio urbano en Chile. En XIII Coloquio Internacional de Geocrítica. El control del espacio y los espacios de control. Barcelona, 5-10 de mayo.

Torres, C. \& Aravena, A. (2016). Trayectorias laborales y transformaciones contemporáneas del trabajo en personas mapuche del Gran Concepción. Revista Chilena de Antropología, (34). Recuperado en: doi:10.5354/0719-1472.2017.45145

Varas, J. (2005). La construcción de la identidad étnica urbana: etnificación y etnogénesis del movimiento mapuche urbano organizado en la ciudad de Santiago. 1990-2000. Universidad de Chile, Santiago. 1990-2000. (Tesis de postgrado). Disponible en http://repositorio. uchile.cl/handle/2250/105968

Vergara, J., Foerster, R. \& Gundermann, H. (2005). Instituciones mediadoras, legislación y movimiento indígena de Dasin a Conadi (1953-1994). Atenea, (491), 71-85.

Vergara, F., Campos, J. \& Farías, F. (2016). La persistencia del Vivir como mapuche. Una aproximación a la identidad étnica de la comunidad mapuche Folil Mapu, en la Región del Maule. CUHSO, Cultura-Hombre-Sociedad, 26(2), 175-207. Recuperado en: doi:10.7770/CUHSO -V26N2-ART1043.

Wittig, F. (2009). Desplazamiento y vigencia del mapudungún en Chile: un análisis desde el discurso reflexivo de los hablantes urbanos. Revista de Lingüística Teórica y Aplicada, 47(2), 135-155.

Zúñiga, N., Aravena, A., Grandón, P., Sáez, F. \& Zañartu, C. (2017). Identidad étnica, discriminación percibida y procesos afectivos en jóvenes mapuches urbanos. CUHSO, Cultura-HombreSociedad, 27(2), 229-250. Recuperado en: doi:10.7770/CUHSOV27N2-ART1226. 